\title{
Prevention of Hypertension at Home
}

\author{
Aris Widiyanto ${ }^{1}$, Santy Irene \\ Putri $^{2}$, Asruria Sani Fajriah ${ }^{3}$, \\ Ahmad Syauqi Mubarok ${ }^{4}$, \\ Joko Tri Atmojo ${ }^{5}$ \\ ${ }^{1}$ Nursing Study Program, \\ Mambaul Ulum Surakarta \\ College of Health Sciences \\ Surakarta, Indonesia \\ ${ }^{2}$ Midwifery Study Program, \\ Tribhuwana Tunggadewi \\ University Malang, Indonesia \\ ${ }^{3}$ Midwifery Study Program, \\ Institute of Health Sciences \\ Strada Indonesia \\ ${ }^{4}$ Master of Public Health, \\ Sebeas Maret University of \\ Surakarta, Indonesia \\ ${ }^{5}$ Nursing Study Program, \\ Mambaul Ulum Surakarta \\ College of Health Sciences \\ Surakarta, Indonesia
}

Email:

widiyantoaris99@gmail.com

Received : May $14^{\text {th }} 2021$

Accepted : May 15 2021

Published : May 20 2021

\begin{abstract}
Hypertension is a systolic blood pressure (SBP) value of $130 \mathrm{mmHg}$ or more and / or a diastolic blood pressure (DBP) of more than 80 $\mathrm{mmHg}$. One of the factors in the development of essential hypertension is the patient's genetic ability to respond to salt. Various non-pharmacological interventions have been shown to be effective in lowering blood pressure and preventing hypertension. The most effective interventions are weight loss, reduced $\mathrm{Na}+$ intake, increased potassium intake, increased physical activity, reduced alcohol consumption and a diet such as Diet Approaches to Stop Hypertension (DASH) which combines several elements that are useful in controlling blood pressure. A diet that emphasized fruit and vegetable intake significantly reduced high blood pressure during the 8-week intervention. Some things we can do to help reduce hypertension at home are to maintain a diet and daily lifestyle and can be done through hydrotherapy (soaking your feet in warm water).
\end{abstract}

Keywords: Preventive, hypertension, diet, blood pressure
Copyright (C) 2021 IIK STRADA Indonesia All right reserved.

This is an open-acces article distributed under the terms of the Creative Commons Attribution-ShareAlike 4.0 International License.

\section{INTRODUCTION}

The definition of hypertension (HTN) is the value of systolic blood pressure (SBP) $130 \mathrm{mmHg}$ or more and / or diastolic blood pressure (DBP) over $80 \mathrm{mmHg}$. Hypertension is one of the most common chronic medical conditions characterized by a continuous increase in arterial pressure (Volpe, Battistoni, Rubattu, \& Tocci, 2019).

Most cases of hypertension are idiopathic which is also known as essential hypertension. It has long been known that increasing salt intake increases the risk of hypertension (Bolívar, 2013). One of the factors explained for the development of essential hypertension is the patient's genetic ability to respond to salt (Mishra, Ingole, \& Jain, 2018) (Choi, Park, \& Ha, 2015). Approximately 50 to $60 \%$ of patients are sensitive to salt and therefore tend to develop hypertension. Factors that cannot be modified include genetics, age, sex, and ethnicity. Meanwhile, the modifiable factors include stress, obesity and nutrition.

a. Age

Age affects the risk factors for hypertension with the highest incidence at the age of 30-40 years. The incidence was $2 \mathrm{X}$ greater in black men, $3 \mathrm{X}$ greater in black men, and $5 \mathrm{X}$ greater for black women. 


\section{b. Gender}

Complications of hypertension increase in a person with male gender (Sandberg \& Ji, 2012).

c. Family history Family

history with hypertension gives a $75 \%$ risk of developing hypertension.

\section{d. Obesity}

Increased body weight in childhood or middle age, the risk of hypertension increases (Jiang, Lu, Zong, Ruan, \& Liu, 2016).

e. Serum lipids An

increase in triglycerides or cholesterol increases the risk of hypertension (Sakurai et al., 2011).

f. Diet

Increased risk with a high sodium diet, increased risk in an industrialized society with a high-fat, highcalorie diet.

g. Smoking. The

risk of developing hypertension is related to the number of cigarettes and the duration of smoking ( $\mathrm{T}$ Liu, 2013).

h. Heredity or Genes

$70 \%-80 \%$ cases of essential hypertension are passed on from parents to children.

\section{i. Job Stress}

Almost everyone in their life experiences stress related to their job. Stress can increase blood pressure for a short period of time, but is unlikely to cause blood pressure to rise over a long period of time. High levels of stress are generally also caused by socioeconomic factors of families, so that indirectly socioeconomic factors also can affect the incidence of hypertension of a person (Mahaguan Putra et al., 2019)

j. Salt Intake

Consumption of salt has a direct effect on blood pressure. There is evidence that those who have a hereditary tendency to suffer from hypertension have a lower ability to excrete salt from their bodies.

k. Physical Activity (Sports)

Exercise is more associated with the management of hypertension because regular and isotonic exercise can lower blood pressure.

The mechanism that controls the constriction and relaxation of blood vessels lies in the vasomotor centers of the medulla in the brain. From this vasomotor begins the sympathetic nerve which continues down the spinal cord and exits the spinal cord column to the sympathetic ganglia in the thorax and abdomen. Central vasomotor stimulation is delivered in the form of impulses that travel downward through the sympathetic nervous system to the sympathetic ganglia. At this point, the preganglionic neurons release acetylcholine which stimulates the postganglionic nerve fibers to the blood vessels. With the release of norepinephrine will cause constriction of blood vessels. Various factors such as anxiety and fear can affect the response of blood vessels to stimulated vasoconstrictors. A person with hypertension is very sensitive to norepinephrine. At the same time that the sympathetic nervous system stimulates blood vessels in response to emotional stimulation, the adrenal glands are also stimulated resulting in additional vasoconstriction activity. The adrenal medulla secretes epinephrine which causes vasoconstriction. The adrenal cortex secretes cortisol and other steroids, which can amplify the vasoconstrictor response of blood vessels. Vasoconstriction resulting in decreased blood flow to the kidneys causes the release of renin (Gareth Beevers, Gregory YH Lip, 2001).

Renin stimulates the formation of angiotensin I which is then converted to angiotensin II which causes a strong vasoconstrictor sutu. This stimulates aldosterone secretion by the adrenal cortex. This hormone causes retention of sodium and water by the renal tubules resulting in intravascular volume. All of these factors tend to cause hypertension. In the elderly, changes in the structure and function of the peripheral vascular system are responsible for the changes in blood pressure that occur. These changes include atherosclerosis, loss of elasticity of the connective tissue and a decrease in the relaxation of vascular smooth muscle which will reduce the tensile strength of the blood vessels. This causes the aorta and large arteries to decrease their ability to accommodate the volume of blood pumped by the heart (volume stroke) resulting in a decrease in cardiac output and an increase in peripheral resistance (Mayet \& Hughes, 2003). Increased body weight in childhood or middle age increases the risk of hypertension 


\section{DISCUSSION}

\section{Hypertension Prevention at Home}

Various non-pharmacological interventions have been shown to be effective in lowering blood pressure and preventing hypertension. The most effective interventions are weight loss, reduced $\mathrm{Na}+$ intake, increased potassium intake, increased physical activity, reduced alcohol consumption and a diet such as Diet Approaches to Stop Hypertension (DASH) which combines several elements that are useful in controlling blood pressure. The DASH diet is very successful when combined with other effective blood pressure-lowering interventions such as reducing sodium intake from food. Lifestyle changes are the best way for individuals to implement these interventions, even small improvements in lifestyle can be of benefit. Government agencies and publicly accessible websites provide useful tips for lifestyle changes and blood pressure monitoring. Routine blood pressure monitoring is very important because it will have a positive effect as a result of lifestyle changes based on individual health maintenance (Filippou et al., 2021) (Bazzano, Green, Harrison, \& Reynolds, 2013).

Two strategies aimed at controlling blood pressure or lowering blood pressure in those at higher risk for developing hypertension were used to implement hypertension prevention interventions. Modeling studies show that a reduction of at least $2 \mathrm{mmHg}$ in diastolic blood pressure results in a 17\% reduction in the incidence of hypertension, a $14 \%$ reduction in the risk of stroke and transient ischemic attack, and a $6 \%$ reduction in the risk of coronary heart disease. Public health interventions focused on improving diet and increasing physical activity are known to be basic strategies for lowering blood pressure. The nutritional pattern of the general public can be influenced by means of public health education campaigns, food product labeling, and collaboration with food manufacturers to reduce the calorie and sodium content of their products, as well as collaboration with fast food companies and restaurants to reduce portions and promote more food preparation. healthy. Physical activity can be increased by making it easier for community members to engage in routine activities (Oparil et al., 2018).

A diet that emphasizes fruit and vegetable intake significantly reduces high blood pressure during the 8-week intervention ( $\mathrm{Lu} \mathrm{Wang,} \mathrm{2012).} \mathrm{WHO} \mathrm{recommends} \mathrm{preventing} \mathrm{and} \mathrm{controlling} \mathrm{blood}$ pressure by reducing and managing stress, a healthy diet consisting of lots of fresh fruits and vegetables that provide nutrients such as potassium and fiber, limiting sodium intake, being aware that many processed foods are high in salt, sugar, coffee and liquor. In addition, avoid foods with high sodium levels, limit your intake of foods high in saturated fat, maintain ideal body weight, do physical activity, avoid smoking, avoid alcohol use, regularly check blood pressure, prevent and treat other medical conditions such as diabetes because about $60 \%$ of people with diabetes also have high blood pressure (Campbell \& Niebylski, 2014).

Calcium is one of the main nutritional components in dairy products. Calcium diet can decrease the activity of the renin-angiotensin system, improve sodium-potassium balance, and inhibit vascular constriction of smooth muscle cells. The high intake of calcium facilitates increased insulin sensitivity which contributes to the reduction of blood pressure. Evidence from epidemiological studies has supported an association between adequate calcium intake and lowering hypertension or reduced risk. Increasing calcium levels in diits can reduce the risk of high blood pressure and can lower blood pressure in people with hypertension (Vaidya, 2015) (Kim, Bu, \& Choi, 2012).

Calcium plays a role in muscle contraction and relaxation, nerve function, blood clotting, blood pressure and immune function. Source of calcium 73\% from milk, 9\% from fruit and vegetables, 5\% from cereals. Clinical studies report that calcium supplementation has an effect on reducing systolic blood pressure $(0.8 \mathrm{mmHg})$ but has no effect on diastolic blood pressure. Fruits and vegetables are foods that are rich in potassium and calcium. The presence of potassium and calcium in the blood will have an effect on reducing sodium levels in the blood. Potassium, in addition to playing a role in creating osmotic balance and acid-base balance of body fluids. Potassium also has the ability to strengthen blood vessel walls so that they remain elastic. A low-calcium diet can result in elevated blood pressure possibly because a low-calcium diet increases the effect of a high- $\mathrm{NaCl}$ diet on blood pressure. Conversely, a diet high in calcium can cause a decrease in blood pressure through diuretic effects, membrane stability effects, effects on sympathetic tone and vasodilators.

Physical activity is defined as the movement of all limbs produced by contraction of the skeletal muscles which increases energy expenditure and consists of daily routine tasks such as commuting, office work or household activities, as well as other movements / activities. Physical exercise is one component of physical activity that is planned, structured, and repetitive with the aim of improving or maintaining health. Physical fitness is defined as a measurable attribute that a person has or can achieve 
in relation to his ability to perform physical activity without excessive fatigue and reflects a combination of physical activity, genetic potential, and health behavior of various organ systems.

Physical activity such as walking that includes an accumulated count of steps per day (e.g. 10,000 steps / day) goes hand in hand with interventions designed to increase daily levels of physical activity. Evidence on whether a day's accumulation of footsteps provides a benefit in lowering blood pressure is limited. An intervention pedometer-based meta-analysis collected data from 12 studies in which a total of 468 mostly normotensive participants showed significant reductions in systolic and diastolic blood pressure by $3.8 \mathrm{mmHg}$ and $0.3 \mathrm{mmHg}$, respectively. Recently, study findings of a pedometer-based workplace intervention with the overall goal of increasing physical activity walking by 10,000 steps / day found that blood pressure was significantly reduced with changes shown to be linearly associated with the number of steps taken. These findings are consistent among all samples and it is advisable to walk 10,000 steps / day because it is effective in reducing blood pressure (Diaz \& Shimbo, 2013).

Smoking can cause hypertension due to chemicals contained in tobacco that can damage the inner lining of the artery walls, making the arteries more prone to plaque buildup (atherosclerosis). This is mainly caused by nicotine which can stimulate the sympathetic nerves so that it spurs the heart to work harder and causes constriction of blood vessels, as well as the role of carbon monoxide which can replace oxygen in the blood and force the heart to meet the body's oxygen needs. Smokers are two to four times more likely to suffer from heart disease and hypertension. When smoking, harmful substances enter the body, especially the heart, for example nicotine. When nicotine enters the body, it can reduce the level of oxygen that can enter the blood. This addictive substance can also speed up the heart rate, raise blood pressure, damage blood vessels in the heart, and increase the likelihood of blood clots that can trigger a heart attack. Likewise with the adverse effects on other organs (Talukder et al., 2011; Tan et al., 2018).

\section{Hypertension Home Care}

\section{Maintaining ideal body weight}

When dealing with hypertension management, weight is crucial. People who are obese should reduce their weight. While people with ideal body weight, avoid weight gain as much as possible. Even reducing body weight by $4-5 \mathrm{~kg}$ can prevent a rise in blood pressure.

\section{Reduce Salt}

Savory and delicious food is tempting. However, you should avoid foods with high salt levels so that high blood pressure can return to normal. Handling hypertension by eating a menu that is low in sodium is the right step. As much as possible avoid over-processed foods and do not need to add extra salt in food.

\section{Monitor blood pressure}

For people with hypertension, you should always provide a blood pressure measuring device to monitor blood pressure conditions. Usually, high blood pressure occurs without any previous symptoms.

\section{Reduce alcohol consumption}

Consuming too much alcohol can also cause high blood pressure to rise. Reducing or even quitting alcohol consumption is a wise choice.

\section{Consumption of nutritious foods}

It is also important to filter out any food that enters the body. Don't just eat foods that are delicious but not friendly to the body. It would be much better to eat nutritious foods to keep blood pressure normal. We can eat fruits and vegetables, especially those high in potassium. Also avoid consuming excess calories, fat and sugar. 
6. Exercise regularly.

Choose the type of exercise that you like is also a way of dealing with hypertension. Find sports that are in accordance with their respective health conditions. Exercise can help keep blood pressure normal. For those just starting out, try exercising for 30 minutes at least 2-3 times per week.

7. Soaking your feet with warm water.

Hydrotherapy can lower blood pressure if you do it regularly. The methods commonly used in hydrotherapy include soaking your feet using warm water. Scientifically warm water has a physiological impact on the body. The first has an impact on the blood vessels where the warmth of the water makes blood circulation smooth, the second is the loading factor in the water which will strengthen the muscles and ligaments that affect the joints of the body. Non-pharmacological treatment can be done by changing a healthier lifestyle and doing therapy by soaking your feet using warm water that can be done any time. The effect of soaking feet using warm water is the same as walking barefoot for 30 minutes (Santoso \& Agung, 2015).

\section{Foods that are easily found in everyday life to reduce hypertension}

\section{Watermelon}

Watermelon contains an amino acid called citrulline, which can help manage high blood pressure. Citrulline helps the body produce nitric oxide, a gas that relaxes blood vessels and promotes flexibility in the arteries. This effect helps blood flow, which can lower high blood pressure.

\section{Kiwi}

The bioactive substances in kiwi cause a reduction in blood pressure. Kiwi is also high in vitamin $\mathrm{C}$, which can significantly contribute to the regulation of blood pressure in the body.

\section{Banana}

Banana is a fruit that contains high potassium. These nutrients are what make bananas a high bloodlowering food.

\section{Kuaci}

Several types of seeds such as sunflower seeds and pumpkin seeds have been shown to contain potassium, magnesium and other minerals that can reduce blood pressure.

\section{Olive oil}

oil is an example of a healthy fat diet. Olive oil contains polyphenols, which are inflammatory compounds that can help reduce blood pressure.

\section{Oatmeal}

Oatmeal is a food that is high in fiber, low in fat, and low in sodium. These nutrients are good for helping lower blood pressure. Eating oatmeal for breakfast is a great way to refuel for the day.

\section{Garlic}

Garlic is a high blood-lowering food because it can increase nitric oxide levels in the body. Nitric oxide can help increase vasodilation or dilation of the arteries which results in lowering high blood pressure. 


\section{Celery}

The hexane extract in celery plays a lot in lowering blood pressure. In addition, celery also contains methanol and ethanol extract. These substances can improve circulation, reduce inflammation and help blood pressure.

\section{Green vegetables}

Potassium contained in green vegetables can help the kidneys excrete more sodium through urine. Examples: Lettuce, Cabbage, Green Radish, Mustard, and Spinach.

10. Temulawak

Temulawak is a native Indonesian plant which is traditionally used to treat various diseases, including hypertension. Temulawak is proven to contain flavonoids which have the function of protecting the vascular endothelium.

\section{Ginger}

Root has been shown to improve blood circulation and relax the muscles around blood vessels, thereby lowering blood pressure.

\section{Foods to Avoid / Restrict in Preventing Hypertension}

\section{Packaged}

meat Meat that has been processed and stored in packaging is the most important high blood pressure food. Because, this product contains a lot of sodium. One example is sausage. When this processed meat is processed, usually there will be the addition of salt.

\section{Frozen}

foods Not all frozen food is "haram" for people with high blood pressure. Frozen foods that are high in sodium should be avoided. For example pizza, because it can contain $700 \mathrm{mg}$ of sodium in one slice. Apart from being a flavor enhancer, sodium in frozen foods can also be useful as a preservative.

\section{Canned Food Canned}

foods, such as sardines and corned beef, tend to be high in sodium. Similar to frozen food, sodium in canned food also functions as a preservative to make it last longer.

\section{Fast food}

The salt content in fast food (fast food) can be very high. This happens because salt is an important requirement to increase the taste of pleasure. In addition, fast food contains trans fats and saturated fats which can increase the risk of increasing blood cholesterol levels. In the end, this high cholesterol can increase high blood pressure.

\section{Sugar}

It's not just salt, in fact, sugar can also affect blood pressure. Unconsciously, sugar is contained in various daily foods that you consume, such as cakes, breads, donuts, candy, and other snacks.

\section{Margarine}

This product is often used when cooking cakes or when eating bread. Hypertension sufferers should avoid consuming foods that contain lots of butter or margarine because they contain high enough salt and saturated fat. 


\section{Alcohol}

Studies suggest that consumption of three glasses of alcohol or more can cause high blood pressure. If large amounts of alcohol are consumed regularly, blood pressure can be difficult to control.

\section{Chicken skin}

One of the nicest parts of chicken is the skin. Especially if cooked until crisp. However, this delicious part is the unhealthy part of chicken. Chicken skin contains high cholesterol. In addition, in processing, often a lot of salt is added.

\section{Salted fish}

Avoid eating salted fish too often and too much. The salt content in salted fish is clearly very high. However, if you only want salted fish once in a while, for example once every 1-2 months, that's fine. When eating salted fish, do not combine it with other foods that are high in salt.

\section{Tomato sauce}

Similar to processed meats, foods such as tomato sauce, chili sauce, and similar pasta are also sources of sodium which are dangerous if consumed by people with hypertension. Just imagine, half a cup of tomato sauce can contain more than $600 \mathrm{mg}$ of sodium.

\section{Soft drinks}

Soft drinks contain mostly only sugar and calories without other nutrients. One can of soda generally contains more than 9 teaspoons of sugar or a total of 39 grams, which is even more than the maximum recommended amount of added sugar per day.

\section{Foot Soak Technique Using Warm Water Helps Reduce Hypertension}

1. Preparation of tools: Chair, basin, thermometer, hot water, cold water, towels, stopwatch, tension meter, stethoscope

2. Tool brought

3. Sitting position on chair

4. Measure blood pressure before doing warm water foot bath

5. Enter warm water into the basin with a temperature of $38-40^{\circ} \mathrm{C}$ (measure using a thermometer)

6. Dip and soak the feet until the ankles leave for 20-30 minutes, if the temperature drops then add warm water until it fits again.

7. When finished, lift your feet then dry with a towel

8. Measure the blood pressure again after the foot bath therapy.

\section{CONCLUSION}

Some things we can do to help reduce hypertension at home are to maintain a diet and daily lifestyle and can be done through hydrotherapy (soaking your feet in warm water).

\section{CONFLICTS OF INTEREST}

The author declares that they have no conflict of interest

\section{REFERENCES}

Bazzano, L. A., Green, T., Harrison, T. N., \& Reynolds, K. (2013). Dietary approaches to prevent hypertension. Current Hypertension Reports, 15(6), 694-702. https://doi.org/10.1007/s11906$013-0390-z$

Bolívar, J. J. (2013). Essential hypertension: An approach to its etiology and neurogenic pathophysiology. International Journal of Hypertension, 2013. https://doi.org/10.1155/2013/547809

Campbell, N. R. C., \& Niebylski, M. L. (2014). Prevention and control of hypertension. Current Opinion in Cardiology, 29(4), 324-330. https://doi.org/10.1097/hco.0000000000000067

Choi, H. Y., Park, H. C., \& Ha, S. K. (2015). Salt sensitivity and hypertension: A paradigm shift from 
kidney malfunction to vascular endothelial dysfunction. Electrolyte and Blood Pressure, 13(1), 7-16. https://doi.org/10.5049/EBP.2015.13.1.7

Diaz, K. M., \& Shimbo, D. (2013). Physical activity and the prevention of hypertension. Current Hypertension Reports, 15(6), 659-668. https://doi.org/10.1007/s11906-013-0386-8

Filippou, C. D., Thomopoulos, C. G., Kouremeti, M. M., Sotiropoulou, L. I., Nihoyannopoulos, P. I., Tousoulis, D. M., \& Tsioufis, C. P. (2021). Mediterranean diet and blood pressure reduction in adults with and without hypertension: A systematic review and meta-analysis of randomized controlled trials. Clinical Nutrition, 1150-1160. https://doi.org/10.1016/j.clnu.2021.01.030

Gareth Beevers, Gregory Y H Lip, E. O. (2001). The pathophysiology of hypertension. BMJ Journal, 322, 912-916. https://doi.org/10.4103/0973-1482.157314

Jiang, S. Z., Lu, W., Zong, X. F., Ruan, H. Y., \& Liu, Y. (2016). Obesity and hypertension. Experimental and Therapeutic Medicine, 12(4), 2395-2399. https://doi.org/10.3892/etm.2016.3667

Kim, M. H., Bu, S. Y., \& Choi, M. K. (2012). Daily calcium intake and its relation to blood pressure, blood lipids, and oxidative stress biomarkers in hypertensive and normotensive subjects. Nutrition Research and Practice, 6(5), 421-428. https://doi.org/10.4162/nrp.2012.6.5.421

Lu Wang, J. E. M. (2012). Fruit and vegetable intake and the risk of hypertension. American Journal of Hypertension, 25(2), 1-7. https://doi.org/10.1038/ajh.2011.186.Fruit

Mahaguan Putra, M., Kadek Nova Darmayasa, I., Agus Winduyasa Bukian, P., Widiyanto, A., Tri Atmojo, J., Tinggi Ilmu Kesehatan Buleleng, S., Tinggi Ilmu Kesehatan Mamba, S., \& Surakarta, U. (2019). HUBUNGAN KEADAAN SOSIAL EKONOMI DAN TINGKAT STRES DENGAN KEJADIAN HIPERTENSI. In Jurnal Ilmiah Keperawatan (Vol. 7, Issue 2). https://akperinsada.ac.id/e-jurnal/index.php/insada/article/view/150

Mayet, J., \& Hughes, A. (2003). Cardiac and vascular pathophysiology in hypertension. Heart, 89(9), 1104-1109. https://doi.org/10.1136/heart.89.9.1104

Mishra, S., Ingole, S., \& Jain, R. (2018). Salt sensitivity and its implication in clinical practice. Indian Heart Journal, 70(4), 556-564. https://doi.org/10.1016/j.ihj.2017.10.006

Oparil, S., Acelajado, M. C., Bakris, G. L., Berlowitz, D. R., Cífková, R., Dominiczak, A. F., ... Whelton, P. K. (2018). Hypertension. Nature Reviews Disease Primers, 4. https://doi.org/10.1038/nrdp.2018.14

Sakurai, M., Stamler, J., Miura, K., Brown, I. J., Nakagawa, H., Elliott, P., ... Zhao, L. (2011). Relationship of dietary cholesterol to blood pressure: The INTERMAP study. Journal of Hypertension, 29(2), 222-228. https://doi.org/10.1097/HJH.0b013e32834069a5

Sandberg, K., \& Ji, H. (2012). Sex differences in primary hypertension. Biology of Sex Differences, 3(1), 7. https://doi.org/10.1186/2042-6410-3-7

Santoso, \& Agung, D. (2015). Pengaruh Terapi Rendam kaki Air Hangat Terhadap Penurunan Tekanan Darah Pada Lansia Penderita Hipertensi. Universitas Tanjung Pura.

T Liu, R. T. (2013). Association between daily cigarette consumption and hypertension moderated by CYP2A6 genotypes in Chinese male current smokers. Journal of Human Hypertension, 27(1), 2430. https://doi.org/10.1038/jhh.2011.111.Association

Talukder, M. A. H., Johnson, W. M., Varadharaj, S., Lian, J., Kearns, P. N., El-Mahdy, M. A., ... Zweier, J. L. (2011). Chronic cigarette smoking causes hypertension, increased oxidative stress, impaired NO bioavailability, endothelial dysfunction, and cardiac remodeling in mice. American Journal of Physiology - Heart and Circulatory Physiology, 300(1), 388-396. https://doi.org/10.1152/ajpheart.00868.2010

Tan, J., Zhang, X., Wang, W., Yin, P., Guo, X., \& Zhou, M. (2018). Smoking, blood pressure, and cardiovascular disease mortality in a large cohort of chinese men with 15 years follow-up. International Journal of Environmental Research and Public Health, 15(5). https://doi.org/10.3390/ijerph15051026

Vaidya, A. (2015). The Renin-Angiotensin-Aldosterone System and CalciumRegulatory Hormones. Journal of Human Hypertension, 29(9), 515-521. https://doi.org/10.1038/jhh.2014.125.The

Volpe, M., Battistoni, A., Rubattu, S., \& Tocci, G. (2019). Hypertension in the elderly: Which are the blood pressure threshold values? European Heart Journal, Supplement, 21, B105-B106. https://doi.org/10.1093/eurheartj/suz023 